\title{
High Density Lipoprotein 2 \\ Relationship of the Plasma Levels of This Lipoprotein Species to Its Composition, to the Magnitude of Postprandial Lipemia, and to the Activities of Lipoprotein Lipase and Hepatic Lipase
}

Josef R. Patsch, Sarada Prasad, Antonio M. Gotto, Jr., and Wolfgang Patsch

Department of Medicine, Baylor College of Medicine and The Methodist Hospital, Houston, Texas 77030

\begin{abstract}
Lipoprotein lipase (LPL) activity in postheparin plasma of 38 normolipidemic volunteers was related to the magnitude of postprandial lipemia after a fat meal, to triglyceride content of high density lipoprotein $2\left(\mathrm{HDL}_{2}\right)$, to hepatic lipase (HL) activity, and to $\mathrm{HDL}_{2}$ levels. LPL activity correlated indirectly with lipemia, triglyceride content of $\mathrm{HDL}_{2}, \mathrm{HL}$ activity, and levels of $\mathrm{HDL}_{2}$ but not of $\mathrm{HDL}_{3}$. HL activity correlated directly with lipemia and indirectly with $\mathrm{HDL}_{2}$ levels.

Triglyceride content of $\mathrm{HDL}_{2}$ correlated directly with lipemia and indirectly with $\mathrm{HDL}_{2}$ levels. In $\mathrm{HDL}_{2}$, abundance of apolipoprotein (apo) A-II and the apoA-I/apoA-II ratio varied widely. The latter correlated positively with LPL activity and $\mathrm{HDL}_{2}$ levels, and, inversely, with HL activity, lipemia, and triglyceride content of $\mathrm{HDL}_{2}$. The study suggests that HDL-cholesterol is not an independent parameter of lipid transport, but is strongly affected by triglyceride metabolism through lipolytic enzymes, as exemplified by postprandial lipemia that affect both composition and plasma levels of $\mathrm{HDL}_{2}$.
\end{abstract}

\section{Introduction}

The negative association between coronary heart disease (CHD) ${ }^{1}$ and high density lipoprotein (HDL)-cholesterol (1-4) has been found to be at least as powerful as correlations between CHD and all other known risk factors (5). Of the two major HDL subfractions $(6,7)$, the plasma levels of $\mathrm{HDL}_{2}$, but not of $\mathrm{HDL}_{3}$, correlate strongly with HDL-cholesterol $(8,9)$, which suggests that the epidemiological data that relate risk of CHD to HDLcholesterol are correlated with the $\mathrm{HDL}_{2}$ fraction.

The mechanism(s) underlying the negative association between $\mathrm{CHD}_{\text {and }} \mathrm{HDL}_{2}$ is unknown. $\mathrm{HDL}_{2}$ could directly interfere with the atherosclerotic process by playing a major role in the "reverse cholesterol transport" (10). Alternatively, $\mathrm{HDL}_{2}$ could be an indicator for a state of lipid transport that protects against atherosclerosis. For instance, among all the lipid or lipoprotein variables in fasting plasma, $\mathrm{HDL}_{2}$ is most reliable and

Address correspondence to Dr. J. R. Patsch, Baylor College of Medicine and The Methodist Hospital, M.S. A601, One Baylor Plaza, Houston, TX 77030. 1987.

Received for publication 23 July 1986 and in revised form 1 April

1. Abbreviations used in this paper: apo, apolipoprotein; CHD, coronary heart disease; HL, hepatic lipase; LPL, lipoprotein lipase; TG, triglyceride.

J. Clin. Invest.

(C) The American Society for Clinical Investigation, Inc.

0021-9738/87/08/0341/07 \$2.00

Volume 80, August 1987, 341-347 sensitive in predicting a normolipidemic individual's capacity to clear triglyceride (TG)-rich lipoproteins from the plasma (8). This significant finding has raised these questions: $(i)$ Do the differences in postprandial lipemia contribute to the large differences in $\mathrm{HDL}_{2}$ levels, and (ii) can the pronounced differences in the magnitude of postprandial lipemia among normolipidemics arise from differences in lipase activities?

To answer these questions we formulated the hypothesis that lipoprotein lipase (LPL) activity limits the magnitude of postprandial lipemia, which determines the TG content of $\mathrm{HDL}_{2}$ that, in turn, affects the levels of $\mathrm{HDL}_{2}$ through the action of hepatic lipase (HL). To test this hypothesis, we administered an oral fat load to normolipidemic individuals as index of TG clearance, analyzed levels and composition of $\mathrm{HDL}_{2}$, and determined the activities of LPL and HL in postheparin plasma. We report, consistent with our hypothesis, that the lower the activity of LPL, the greater is the magnitude of postprandial lipemia and the TG content of $\mathrm{HDL}_{2}$, and consequently the lower the plasma concentration of $\mathrm{HDL}_{2}$. Opposite associations were found with $\mathrm{HL}$.

\section{Methods}

Study subjects. This study was approved by the Human Subject Review Committee of Baylor College of Medicine, and informed consent was obtained from participants. Volunteers were recruited by announcement at the institution campus and participation in the study was remunerated. 41 subjects were enlisted as outpatients for three visits within 3 wk. Each subject was instructed to adhere to his/her usual diet and alcohol intake for this time period. Blood was obtained in the morning between 7:30 and 9:30 a.m. in the postabsorptive state, i.e., $~ 14 \mathrm{~h}$ after ingestion of a light dinner and no more than $30 \mathrm{~g}$ of ethanol. All blood samples were collected in tubes containing $1.5 \mathrm{mg} / \mathrm{ml}$ EDTA. The plasma specimens from the first visit were analyzed for cholesterol, TG, and HDL-cholesterol. At this stage of the study, three individuals were excluded because of cholesterol and/or TG levels elevated above the 95th percentile of normal age- and sex-matched subjects (11). Of the remaining 38 individuals, 13 were females and 25 were males, ranging in age from 21 to 42 yr. During the second visit, an oral fat-tolerance test was performed. A third visit was scheduled within 2 wk after the second visit to obtain a blood sample in the postabsorptive state, repeat lipid analysis, and perform HDL subfraction and apoprotein quantification. During this visit, heparin was injected intravenously and, after $15 \mathrm{~min}$, a second blood sample was obtained for determining the activities of LPL and $\mathrm{HL}$ in postheparin plasma.

Test meal. A standard liquid fatty meal, whose composition and preparation have been described in detail previously (8), was administered orally in the postabsorptive state. Each individual ingested $65 \mathrm{~g} \mathrm{fat} / \mathrm{m}^{2}$ body surface. Blood samples were collected in the postabsorptive state and at 2, 4, 6, and $8 \mathrm{~h}$ after ingestion of the fat meal. The magnitude of postprandial lipemia was quantified as the area under the time-dependent TG-level curve, and is expressed as milligrams per deciliter plasma times 8-h TG area (8).

Quantification of $H D L_{2}$. Concentrations of $\mathrm{HDL}_{2}$ and $\mathrm{HDL}_{3}$ in postabsorptive plasma were quantified by two independent procedures. 
The first procedure involved stepwise precipitation of apolipoprotein (apo) B-containing lipoproteins (12) followed by precipitation of $\mathrm{HDL}_{2}$ (13). Cholesterol was quantified in the respective supernatants. In this way, HDL-cholesterol and $\mathrm{HDL}_{3}$-cholesterol were measured, and $\mathrm{HDL}_{2}$ cholesterol was estimated by subtracting the latter from the former (13). The second quantification of HDL subfractions used zonal ultracentrifugation (7). Rotor fractions under the $\mathrm{HDL}_{2}$ and $\mathrm{HDL}_{3}$ peaks were pooled and analyzed for lipid and protein components. Lipid phosphorus was determined by the procedure of Bartlett (14); TG, by an enzymatic method (Triglycerides GPO; Boehringer Mannheim, GmbH, Mannheim, FRG); cholesterol and cholesteryl esters, by the High Performance K enzymatic method (15) (Boehringer Mannheim GmbH); and protein was quantified by the method of Lowry et al. (16), using bovine serum albumin (BSA) as standard. In this way, the plasma levels of all major lipid components, and of $\mathrm{HDL}_{2}$ and $\mathrm{HDL}_{3}$ protein could be determined, from which the concentrations of the entire $\mathrm{HDL}_{2}$ and $\mathrm{HDL}_{3}$ particle mass were calculated (7). Cholesterol recovered from the two zonally isolated HDL fractions averaged $93.8 \%$ of HDL-cholesterol.

For determination of $\mathrm{HDL}_{2}$-cholesterol, zonal ultracentrifugation (7) and sequential precipitation (13) gave satisfactory agreement. By using the former method we obtained mean levels for $\mathrm{HDL}_{2}$-cholesterol of $13 \pm 10 \mathrm{mg} / \mathrm{dl}$ (range between 2 and $35 \mathrm{mg} / \mathrm{dl}$ ), and by the latter method, mean levels of $15 \pm 12 \mathrm{mg} / \mathrm{dl}$ (range between 0 and $45 \mathrm{mg} / \mathrm{dl}$ ). The correlation coefficient was 0.90 , and $P<0.0001$. Because of this agreement, all comparisons of $\mathrm{HDL}_{2}$ levels with other parameters of lipid transport were very similar for both methods of $\mathrm{HDL}_{2}$ quantification. Total HDLcholesterol, for example, correlated with $\mathrm{HDL}_{2}$ from zonal ultracentrifugation at $r=0.83(P<0.0001)$ and from precipitation at $r=0.88(P$ $<0.0001$ ). All correlations, presented in this report, are given for the entire set of study subjects. When analyzed for males and females separately, no major differences in the levels of significance were found.

Other laboratory procedures. Cholesterol and TG in plasma were measured by automated, enzymatic procedures $(17,18)$. ApoA-I, apoAII, and apoB were measured in plasma and in zonally isolated HDL fractions by respective double-antibody radioimmunoassay procedures (19-21). For quantification of apoA-I, 0.35\% Tween-20 was included in the borate-BSA buffer system for adequate exposure of apoA-I immunoreactivity (22). ApoA-I and apoA-II recovered from the zonally isolated HDL fractions averaged 91 and $94 \%$ of plasma apoA-I and apoA-II, respectively.

To release LPL and HL into the circulation, heparin sodium, U.S. Pharmacopeia from beef lung, was used (Upjohn Co., Kalamazoo, MI). A blood sample was drawn in the postabsorptive state (preheparin plasma), then $2,280 \mathrm{U} / \mathrm{m}^{2}$ heparin was administered intravenously. A second blood sample (postheparin plasma) was obtained $15 \mathrm{~min}$ after injection of heparin. Plasma was immediately separated by centrifugation at $4^{\circ} \mathrm{C}$ and stored at $-70^{\circ} \mathrm{C}$. Activities of LPL and HL were determined according to Huttunen et al. (23), using a $\left[{ }^{14} \mathrm{C}\right]$ triolein-labeled substrate and an antiserum directed against HL. For assay of LPL, samples were preincubated with antiserum against human HL sufficient to inhibit $>95 \%$ of $\mathrm{HL}$ activity. HL was assayed in $1 \mathrm{M} \mathrm{NaCl}$. All samples were analyzed in triplicate within one assay. This analysis was repeated in a second assay using a second set of aliquots of frozen-plasma samples. Mean interassay coefficient of variation was $7.2 \%$ for LPL and $5.2 \%$ for HL.

Validation of $H L$ assay. Before its application in this study, the assay was evaluated in the presence of greatly varying amounts of $\mathrm{HDL}_{2}$ and $\mathrm{HDL}_{3}$ in postheparin plasma. $\mathrm{HL}$ is a single enzyme molecule displaying TG lipase, monoglyceride lipase, and phospholipase activities (24). TG and phospholipids of $\mathrm{HDL}_{2}$ serve as substrates for $\mathrm{HL}$ (25), and $\mathrm{HDL}_{2}$ compete with native TG-rich lipoproteins and artificial TG-rich emulsions as substrate for the enzyme (26). Endogenous $\mathrm{HDL}_{2}$, when present in high amounts in a given plasma specimen to be assayed, could potentially compete with the exogenous substrate and thereby reduce the observed lipase activity. Using postheparin plasma for the lipase assays could further aggravate such interference. Injection of heparin enhances clearance of TG-rich lipoproteins and transfer of their surface components, mainly phospholipids, to HDL (27), thereby increasing HDL components that are able to compete for the enzyme activity. Such interference has indeed been suggested by some authors $(28)$, but dismissed by others $(29,30)$. To resolve this issue, we isolated and quantified $\mathrm{HDL}_{2}$ and $\mathrm{HDL}_{3}$ from the pre- and postheparin plasma of two individuals (7), one male and one female. Comparison of preheparin to postheparin plasma showed that $\mathrm{HDL}_{2}$ levels rose by 2 and $6 \%$, and $\mathrm{HDL}_{3}$ levels were altered by -2 and 3\%, respectively. These HDL preparations were titrated to HL-assay mixtures using the postheparin plasma of a male representative of our study subjects to determine the inhibitory effect of HDL fractions on apparent $\mathrm{HL}$ activity against the artificial $\left[{ }^{14} \mathrm{C}\right]$ triolein substrate. As summarized in Fig. 1, addition of $\mathrm{HDL}_{2}$ and $\mathrm{HDL}_{3}$ indeed reduced the observed activity of $\mathrm{HL}$. However, a $5 \%$ reduction of $\mathrm{HL}$ activity required the addition of $\mathrm{HDL}_{2}$ in concentrations equivalent to $\sim 150 \mathrm{mg} \mathrm{HDL}_{2}$ protein/dl plasma. The levels of $\mathrm{HDL}_{2}$ protein in postabsorptive plasma of our study subjects were much lower, ranging from 2.5 to $44.5 \mathrm{mg} / \mathrm{dl}$ of plasma. Heparin altered the plasma levels of $\mathrm{HDL}_{2}$ and $\mathrm{HDL}_{3}$ by $<10 \%$. Also, $\mathrm{HDL}_{2}$ or $\mathrm{HDL}_{3}$ purified from postheparin plasma did not differ noticeably from their counterparts, preheparin plasma, in their ability to inhibit lipase activities. We conclude, therefore, that low HL activities observed using the described assay (23) are not due to high levels of $\mathrm{HDL}_{2}$ in a given plasma specimen.

\section{Results}

Lipid and apo levels in postabsorptive plasma, the triglyceridemic response to the standardized oral fat load, and the lipase activities in postheparin plasma from the $\mathbf{3 8}$ study subjects are given in Table I. Both $\mathrm{HDL}_{2}$-cholesterol and triglyceridemic responses displayed by far the greatest interindividual variabilities, followed by the activity of LPL as a distant third, but still greater than the remaining parameters. Thus, our study subjects, all normolipidemic in the postabsorptive state, displayed the largest differences both in $\mathrm{HDL}_{2}$ concentrations in postabsorptive plasma and in the TG levels after ingestion of the fatty test meal.

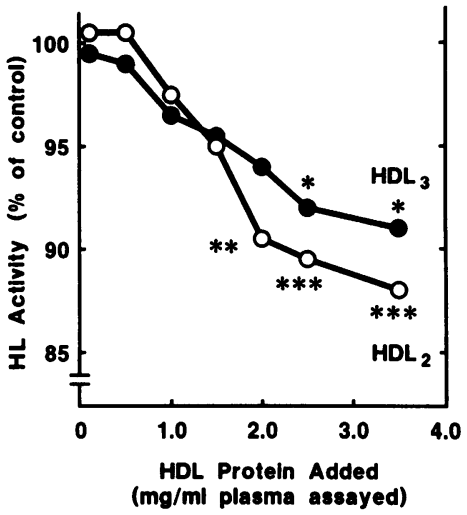

Figure 1. Effect of $\mathrm{HDL}_{2}$ and $\mathrm{HDL}_{3}$ on observed activity of HL. $\mathrm{HDL}_{2}$ and $\mathrm{HDL}_{3}$ were isolated from one female $\left(31 \mathrm{mg} / \mathrm{dl} \mathrm{HDL}_{2}\right.$ cholesterol, $32 \mathrm{mg} / \mathrm{dl}$ $\mathrm{HDL}_{3}$-cholesterol) and one male $(9 \mathrm{mg} / \mathrm{dl}$ $\mathrm{HDL}_{2}$-cholesterol, 35 $\mathrm{mg} / \mathrm{dl} \mathrm{HDL}$-cholesterol) before and $15 \mathrm{~min}$ after injection of heparin. Increasing amounts of each preparation (two

preheparin and two postheparin) of $\mathrm{HDL}_{2}(n=4)$ and $\mathrm{HDL}_{3}(n=4)$ were added to assay mixtures for HL activity. Each mixture contained the same postheparin plasma from a male individual with low $\mathrm{HDL}_{2}$ plasma levels $\left(\mathrm{HDL}_{2}\right.$ protein was $0.15 \mathrm{mg} / \mathrm{ml} ; \mathrm{HDL}_{3}$ protein, $1.0 \mathrm{mg} /$ $\mathrm{ml}$ plasma; and HDL-cholesterol, $51 \mathrm{mg} / \mathrm{dl}$ ). As can be seen, $\sim 1.5$ $\mathrm{mg} \mathrm{HDL} 2$ protein/ml plasma (equivalent to $150 \mathrm{mg} \mathrm{HDL} 2$ protein/dl) was required to reduce apparent activity of $\mathrm{HL}$ by $5 \%$. $\mathrm{HDL}_{2}$ protein in our study subjects ranged from 2.5 to $44.5 \mathrm{mg} / \mathrm{dl}$ plasma. Statistically, significant differences from control value (100\%): $* P<0.02$, ** $P<0.01, * * * P<0.001 ; n=4$. Results obtained with $\mathrm{HDL}_{2}$ and $\mathrm{HDL}_{3}$ from pre- $(n=2)$ and postheparin $(n=2)$ plasma were pooled $(n=4)$ because effects on lipase activity were identical. 
Table I. Lipid and Apo Levels in Postabsorptive Plasma, Triglyceridemic Response, and Lipase Activities in Postheparin Plasma of 38 Study Subjects

\begin{tabular}{|c|c|c|c|c|c|c|c|c|c|c|c|}
\hline & \multirow[b]{2}{*}{ Chol } & \multirow[b]{2}{*}{ TG } & \multirow[b]{2}{*}{ HDL-Ch } & \multirow[b]{2}{*}{$\mathrm{HDL}_{2}-\mathrm{Ch}$} & \multirow[b]{2}{*}{$\mathrm{HDL}_{3}-\mathrm{Ch}$} & \multirow[b]{2}{*}{ ApoA-I } & \multirow[b]{2}{*}{ ApoA-II } & \multirow[b]{2}{*}{ ApoB } & \multirow[b]{2}{*}{$\begin{array}{l}\text { Triglyceridemic } \\
\text { response* }\end{array}$} & \multicolumn{2}{|c|}{$\begin{array}{l}\text { Activity in } \\
\text { postheparin plasma }{ }^{*}\end{array}$} \\
\hline & & & & & & & & & & LPL & HL \\
\hline & $m g / d l^{\prime}$ & $m g / d l$ & $m g / d l$ & $m g / d l$ & $m g / d l$ & $m g / d l$ & $m g / d l$ & $m g / d l$ & & & \\
\hline Mean & 184 & 85 & 54 & 17 & 37 & 155 & 34 & 83 & 501 & 12 & 23 \\
\hline \pm 1 SD & 25 & 31 & 14 & 12 & 7 & 33 & 7 & 22 & 314 & 7 & 9 \\
\hline Range & $131-235$ & $28-159$ & $24-81$ & $0-45$ & $24-52$ & $90-215$ & $21-50$ & $47-145$ & $58-1,338$ & 4-34 & $9-41$ \\
\hline
\end{tabular}

Chol, total cholesterol; HDL-Ch, $\mathrm{HDL}_{2}-\mathrm{Ch}$, or $\mathrm{HDL}_{3}-\mathrm{Ch}$, cholesterol associated with total $\mathrm{HDL}, \mathrm{HDL}_{2}$, or $\mathrm{HDL}_{3}$, respectively. * Triglyceridemic response expressed as milligrams per deciliter times 8-h TG area (8). ${ }^{\ddagger}$ Activity expressed as micromoles of free fatty acids released per milliliter plasma per hour at $28^{\circ} \mathrm{C}$. Milligrams per deciliter of postabsorptive plasma.

The magnitude of postprandial lipemia and the levels of $\mathrm{HDL}_{2}$ in postabsorptive plasma showed a significant negative association (Table II). The association was virtually identical using either the entire $\mathrm{HDL}_{2}$ lipoprotein values obtained by zonal ultracentrifugation or the $\mathrm{HDL}_{2}$-cholesterol values, by the precipitation procedure. Also, this negative association persisted when $\mathrm{HDL}_{2}$-cholesterol was replaced by other $\mathrm{HDL}_{2}$ components such as $\mathrm{HDL}_{2}$-protein, $\mathrm{HDL}_{2}$-phospholipid, or $\mathrm{HDL}_{2}$-TG. $\mathrm{HDL}_{2}$-TG, however, displayed a much weaker association than did the other $\mathrm{HDL}_{2}$ components. No correlation existed between the magnitude of postprandial lipemia and the plasma levels of $\mathrm{HDL}_{3}$ or any of its components.

Because we used zonal ultracentrifugation, in addition to the precipitation technique, we were able not only to quantitate $\mathrm{HDL}_{2}$ and $\mathrm{HDL}_{3}$, but also to characterize these $\mathrm{HDL}$ subfractions (Table III). With a range of $4-115 \mathrm{mg} / \mathrm{dl}$, the interindividual variation in plasma levels of $\mathrm{HDL}_{2}$ was much larger than that of $\mathrm{HDL}_{3}, 170-312 \mathrm{mg} / \mathrm{dl}$. In $\mathrm{HDL}_{2}$, the percentage contributions from protein, phospholipid, and unesterified cholesterol were fairly constant. A higher degree of variability was seen with cholesteryl ester content. By far the highest degree of compositional variation was with the content of TG in $\mathrm{HDL}_{2}$, which varied as much as 7.8-fold among individuals. Quite similar to $\mathrm{HDL}_{2}$, the TG content of $\mathrm{HDL}_{3}$ varied also greatly among individuals. The TG content of $\mathrm{HDL}_{2}$ and $\mathrm{HDL}_{3}$ changed in a parallel fashion $(r=0.81, P<0.0001)$.

Table II. Pearson Correlation Coefficients between the Magnitude of Postprandial Lipemia* and $\mathrm{HDL}_{2}$ Component Levels ${ }^{\ddagger}$ in Postabsorptive Plasma

\begin{tabular}{lll}
\hline & $r$ & $P$ \\
\hline Total HDL $_{2}$ & -0.65 & 0.0001 \\
HDL $_{2}$-cholesterol & & \\
HDL $_{2}$-cholesterol & -0.63 & 0.0001 \\
HDL $_{2}$-phospholipid & -0.61 & 0.0001 \\
HDL $_{2}$-protein & -0.56 & 0.0008 \\
HDL $_{2}$-triglyceride & -0.53 & 0.0018 \\
& -0.39 & 0.0278 \\
\hline
\end{tabular}

* Milligrams per deciliter times 8-h TG area (8).

* Milligrams per deciliter plasma.

Obtained by precipitation method (13). All others obtained by zonal ultracentrifugation (7).
The correlations of LPL activity with the magnitude of postprandial lipemia, TG content of $\mathrm{HDL}_{2}$, plasma levels of $\mathrm{HDL}_{2}$, and total HDL-cholesterol are illustrated in Fig. $2 A$. LPL activity was inversely correlated with alimentary lipemia and TG content of $\mathrm{HDL}_{2}$, but positively correlated with plasma concentrations of $\mathrm{HDL}_{2}$ and with HDL-cholesterol. Fig. $2 B$ compares the activity of $\mathrm{HL}$ with the same parameters. Among these, the inverse correlation between $\mathrm{HL}$ and $\mathrm{HDL}_{2}$ levels was strongest, followed by that of total HDL-cholesterol. Positive associations existed between $\mathrm{HL}$ activity and both, magnitude of postprandial lipemia and TG content of $\mathrm{HDL}_{2}$. The latter, however, did not reach the level of statistical significance (Fig. $2 \mathrm{~B}$ ).

Fig. 3 compares magnitude of postprandial lipemia with TG content of $\mathrm{HDL}_{2}$, plasma levels of $\mathrm{HDL}_{2}$, and HDL-cholesterol. Lipemia displayed a strong positive association with TG content of $\mathrm{HDL}_{2}$, and an equally strong negative association with plasma levels of $\mathrm{HDL}_{2}(r=0.69$ vs. $r=-0.65)$. TG content of $\mathrm{HDL}_{2}$, as the percent $\mathrm{TG}$ of $\mathrm{HDL}_{2}$ mass, was inversely associated with $\mathrm{HDL}_{2}$ levels in plasma $(r=-0.56, P<0.0005)$. In addition to these associations, postprandial lipemia displayed positive correlations with fasting levels of TG $(r=0.59, P<0.0001)$ and apoB $(r=0.50, P<0.001)$ as well as a negative correlation with plasma levels of apoA-I $(r=-0.34, P<0.05)$. Consistent with a previous report (8), these associations, however, were much weaker than that with $\mathrm{HDL}_{2}$ levels. The activities of the two enzymes, LPL and HL, were inversely associated both in males $(r=-0.61, P<0.0001)$ and females $(r=-0.78, P<0.0001)$ as well as in the entire set of subjects $(r=-0.66, P<0.0001)$.

The abundance of apoA-I and apoA-II in $\mathrm{HDL}_{2}$ and $\mathrm{HDL}_{3}$ is summarized in Table IV. In $\mathrm{HDL}_{2}$, apoA-I represented $\sim 80 \%$ of the $\mathrm{HDL}_{2}$ protein. ApoA-II averaged $12 \%$ of the protein, but varied widely, ranging from 4.5 to $29.5 \%$ of the $\mathrm{HDL}_{2}$ protein. This resulted in an apoA-I/apoA-II molar ratio of 4.6 \pm 1.5 , ranging from 1.4 to 7.3. In $\mathrm{HDL}_{3}$, the amount of apoA-II was more than that in $\mathrm{HDL}_{2}$ and exhibited a much lesser degree of variation, which resulted in an apoA-I/apoA-II molar ratio of $1.6 \pm 0.2$, ranging from 1.2 to 2.1 .

Table $\mathrm{V}$ compares abundance of apoA-I and apoA-II in $\mathrm{HDL}_{2}$ with activity of LPL, magnitude of lipemia, TG content of $\mathrm{HDL}_{2}, \mathrm{HL}$ activity, and plasma levels of $\mathrm{HDL}_{2}$. Abundance of apoA-I did not correlate with any of the listed parameters. However, apoA-II in $\mathrm{HDL}_{2}$ correlated positively with TG content of $\mathrm{HDL}_{2}$ and with $\mathrm{HL}$ activity, and, negatively with $\mathrm{HDL}_{2}$ levels in plasma. The apoA-I/apoA-II molar ratio in $\mathrm{HDL}_{2}$ correlated 
Table III. Plasma Levels and Weight-Percentage Composition of $\mathrm{HDL}_{2}$ and $\mathrm{HDL}_{3}$ from 38 Subjects

\begin{tabular}{|c|c|c|c|c|c|c|}
\hline & Total lipoprotein & Protein & PL & UC & $\mathrm{CE}$ & TG \\
\hline & mg/dl plasma & $9 *$ & $\% *$ & $9 *$ & $\% *$ & $\mathscr{W}^{*}$ \\
\hline \multicolumn{7}{|l|}{$\mathrm{HDL}_{2}$} \\
\hline Mean & 41 & 38.6 & 32.5 & 5.2 & 19.3 & 4.5 \\
\hline$\pm \mathrm{SD}$ & 31 & 1.5 & 1.6 & 0.5 & 1.7 & 2.3 \\
\hline Range & 4-115 & $36.1-41.3$ & $30.1-34.6$ & $4.2-6.4$ & $11.8-22.1$ & $1.8-14.0$ \\
\hline \multicolumn{7}{|l|}{$\mathrm{HDL}_{3}$} \\
\hline Mean & 219 & 50.9 & 29.0 & 2.5 & 15.1 & 2.6 \\
\hline$\pm \mathrm{SD}$ & 37 & 2.5 & 2.4 & 0.3 & 1.9 & 1.4 \\
\hline Range & $170-312$ & $46.6-56.4$ & $23.5-35.6$ & $1.8-2.9$ & $8.6-20.6$ & $1.3-9.1$ \\
\hline
\end{tabular}

PL, phospholipid; UC, unesterified cholesterol (387 mol wt); CE, cholesteryl esters (651 mol wt). * Weight-percentage contributions.

positively with LPL and $\mathrm{HDL}_{2}$ levels, and, negatively with alimentary lipemia, TG content of $\mathrm{HDL}_{2}$, and $\mathrm{HL}$ activity.

\section{Discussion}

The fasting plasma levels of $\mathrm{HDL}-$ cholesterol and $\mathrm{HDL}_{2}$ are major discriminators for atherosclerosis. Although it is generally used for assessment of lipid risk factors, the fasting plasma represents an equilibrated state of the lipid transport system in the circulation. This system, however, has individually variable buffering capacity for maintaining homeostasis of lipid transport. When the plasma lipid transport system of normolipidemics is subjected to a physiological challenge such as the intake of a fatty meal, the magnitude of the ensuing postprandial lipemia varies among individuals (8). In fasting plasma, the $\mathrm{HDL}_{2}$ class shows interindividual variations of the same magnitude ranging from 5 to $150 \mathrm{mg} / \mathrm{dl}$ plasma $(8,31)$. Among all parameters of lipid transport in fasting plasma, $\mathrm{HDL}_{2}$ levels exhibit by far the strongest association with postprandial lipemia (8). This phenomenon prompted us to study why postprandial lipemia and $\mathrm{HDL}_{2}$ levels differ so widely among normolipidemic individuals and why they are associated so closely.

In a recent study we observed that, $2-4 \mathrm{~h}$ after ingestion of a fatty meal, plasma TG levels peak and that $\mathrm{HDL}_{2}$ become enriched with TG somewhat later, $\sim 4-8 \mathrm{~h}$ after fat intake (31). The proportion of TG accumulating in the core of $\mathrm{HDL}_{2}$ varies with the magnitude of preceding postprandial lipemia (31). The TG content of $\mathrm{HDL}_{2}$ appears to be very important for the metabolic fate of $\mathrm{HDL}_{2}$ because TG-enriched $\mathrm{HDL}_{2}$ can be converted to $\mathrm{HDL}_{3}$ by $\mathrm{HL}$ in vitro (31). The physiological relevance of this finding is supported by the following observation.

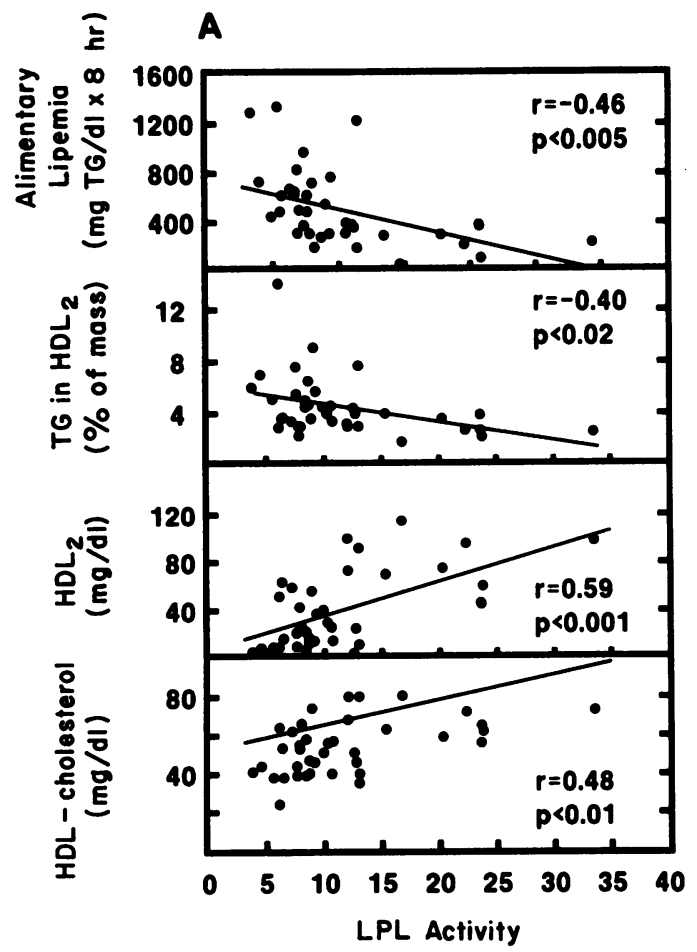

B

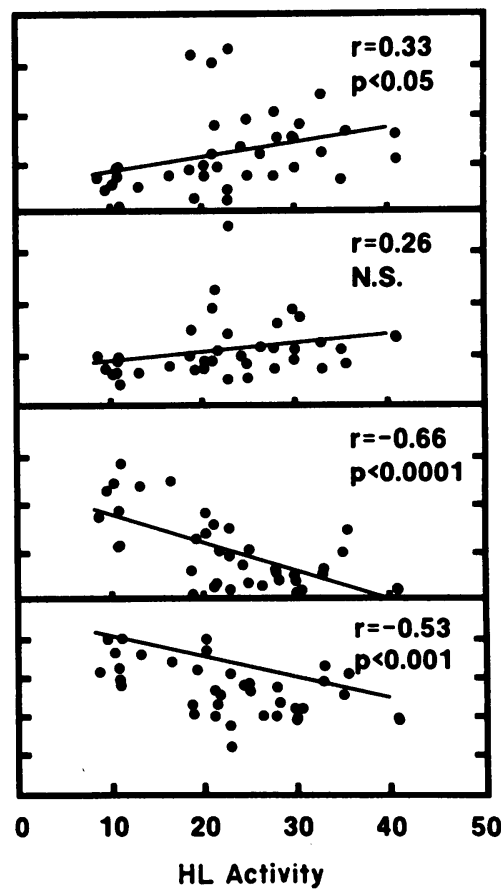

( $\mu \mathrm{mol}$ fatty acids $/ \mathrm{hr} \times \mathrm{ml}$ plasma)
Figure 2. Linear regression analyses comparing the magnitude of alimentary lipemia, TG content of $\mathrm{HDL}_{2}$, the plasma levels of $\mathrm{HDL}_{2}$, and HDL-cholesterol (ordinates) with the activity of LPL $(A)$ and $\mathrm{HL}(B)$ in postheparin plasma (abscissae). 

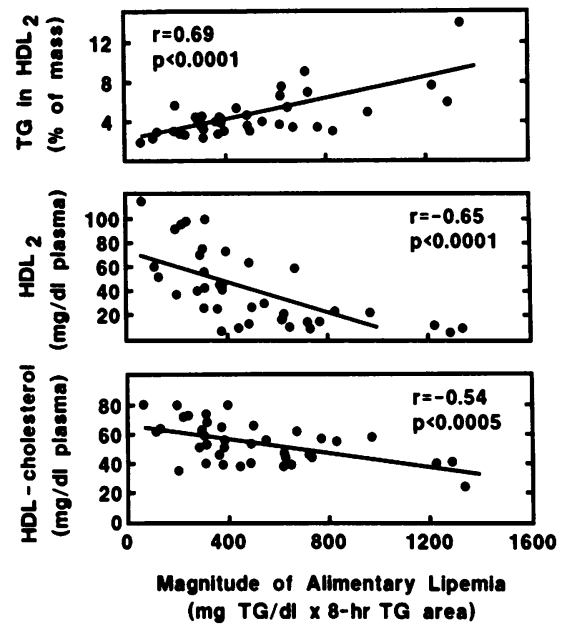

Figure 3. Linear regression analyses comparing TG content of $\mathrm{HDL}_{2}$, $\mathrm{HDL}_{2}$ levels, and HDL-cholesterol (ordinates) with the magnitude of alimentary lipemia. TG content of $\mathrm{HDL}_{2}$ was inversely associated with $\mathrm{HDL}_{2}$ levels $(r=-0.56, P<0.005)$. TG content of $\mathrm{HDL}_{3}$, albeit weaker than that of $\mathrm{HDL}_{2}$, showed also a positive association with the magnitude of lipemia $(r=0.56, P<0.0005)$. No association existed, however, between lipemia and plasma levels of $\mathrm{HDL}_{3}$ nor with TG content of $\mathrm{HDL}_{3}$ and $\mathrm{HDL}_{3}$ levels.

In individuals with pronounced postprandial lipemia, whose $\mathrm{HDL}_{2}$ become TG-rich postprandially, fat intake causes, after 12-15 h, a drop in the levels of $\mathrm{HDL}_{2}$ and a rise in those of $\mathrm{HDL}_{3}(31)$. The data in the study presented here support this notion; the larger postprandial lipemia, the higher is the TG content of $\mathrm{HDL}_{2}$ and the lower are $\mathrm{HDL}_{2}$ levels in plasma (Fig. 3). Based on these findings we propose the relationship schematically illustrated in Fig. 4. Ingestion of fat is followed by the appearance of chylomicrons in plasma whose accumulation in plasma is limited by LPL. Accordingly, its activity is associated inversely with the magnitude of postprandial lipemia (Fig. $2 \mathrm{~A}$ ). With low LPL activity, a pronounced lipemia provides TG for transfer from chylomicrons into $\mathrm{HDL}_{2}$ through the action of lipid transfer proteins (32). By this mechanism, the activity of LPL is associated inversely with TG in $\mathrm{HDL}_{2}$ (Fig. $2 \mathrm{~A}$ ). TG-enriched $\mathrm{HDL}_{2}$ are converted to $\mathrm{HDL}_{3}$ by $\mathrm{HL}$ (31). The result is a low steady state level of $\mathrm{HDL}_{2}$. In this metabolic scenario, LPL would be the origin of a chain of events whose interplay determines $\mathrm{HDL}_{2}$ levels. This view is supported

Table IV. Proportion of ApoA-I and ApoA-II in $H D L_{2}$ and $H D L_{3}$

\begin{tabular}{lllll}
\hline & \multicolumn{2}{l}{ Percent of protein } & & Molar ratio \\
\cline { 2 - 3 } & ApoA-I & ApoA-II & & ApoA-I/ApoA-II \\
\hline HDL $_{2}$ & & & \\
Mean & 80.1 & 12.0 & \\
\pm SD & 6.4 & 5.0 & 4.6 \\
Range & $68.2-97.8$ & $4.5-29.5$ & 1.5 \\
HDL & & & $1.4-7.3$ \\
Mean & 65.7 & 25.7 & \\
\pm SD & 4.3 & 2.6 & 1.6 \\
Range & $57.0-73.7$ & $21.0-31.8$ & 0.2 \\
& & & $1.2-2.1$ \\
\hline
\end{tabular}

by an in vivo experiment in which LPL was selectively blocked. Specific blockage of LPL in the chicken causes massive accumulation of TG-rich lipoproteins, the enrichment of HDL with TG at the expense of cholesteryl esters, and, ultimately, the replacement of the larger $\mathrm{HDL}_{2}$ by smaller, denser $\mathrm{HDL}_{3}(33)$. These direct in vivo findings underscore the importance of LPL in determining the composition and plasma levels of $\mathrm{HDL}_{2}$. Two important factors in this sequence of reactions appear to be lipid transfer protein(s) and HL.

In this study, we have not quantified the activities of lipid transfer protein in plasma. We hypothesize, however, that interindividual differences in lipid transfer activity are not critical for differences in TG content of $\mathrm{HDL}_{2}$ for the following reasons. Postprandial enrichment of $\mathrm{HDL}_{2}$ correlates with the magnitude of postprandial lipemia (31), and TG abundance in $\mathrm{HDL}_{2}$ correlates directly with magnitude of lipemia (Fig. 3). The positive association between plasma TG levels and TG content of HDL in normolipidemic and hypertriglyceridemic individuals has been reported by others (34). Thus, enrichment of $\mathrm{HDL}_{2}$ with TG in man appears to be governed primarily by the relative abundance of donor and acceptor lipoproteins (35).

TG content of $\mathrm{HDL}_{3}$ showed also a positive association with lipemia and paralleled that in $\mathrm{HDL}_{2}(r=0.81)$. TG-enriched $\mathrm{HDL}_{3}$ serve also as substrate for $\mathrm{HL}$ and are converted to particularly small, dense $\mathrm{HDL}_{3}$ (Patsch, J. R., and G. BengtssonOlivecrona, unpublished observations). In some of our study subjects with extremely low $\mathrm{HDL}_{2}$ levels, below $10 \mathrm{mg} / \mathrm{dl}, \mathrm{HDL}_{3}$ levels were also low, and the $\mathrm{HDL}_{3}$ showed higher densities typical for $\mathrm{HDL}_{3 \mathrm{D}}$ (36). This observation is consistent with the view that in individuals with very pronounced lipemia, little $\mathrm{HDL}_{3}$ is formed because of low $\mathrm{HDL}_{2}$ levels. The TG-enriched $\mathrm{HDL}_{3}$ are converted to smaller, denser $\mathrm{HDL}_{3}$, which leads to a predominance of this HDL subspecies as has been observed in hypertriglyceridemic subjects $(36,37)$. Because of this heterogeneity of $\mathrm{HDL}_{3}$, the postulated precursor-product relationship between $\mathrm{HDL}_{2}$ and $\mathrm{HDL}_{3}(27,31)$ does not always have to be reflected in a simple reciprocal association of high $\mathrm{HDL}_{2}$ levels with low $\mathrm{HDL}_{3}$ levels or vice versa.

The second major factor to be considered in this metabolic scenario is HL. According to the scheme outlined in Fig. 4, the TG content of $\mathrm{HDL}_{2}$ rather than the activity of the enzyme would determine whether or not $\mathrm{HDL}_{2}$ is converted to $\mathrm{HDL}_{3}$

Table V. Pearson Correlation Coefficients between the Relative Proportion of ApoA-I and ApoA-II in HDL $\mathrm{H}_{2}^{*}$ and Other Parameters of Lipid Transport

\begin{tabular}{|c|c|c|c|}
\hline & \multicolumn{2}{|c|}{$\begin{array}{l}\text { Percentage of the two major } \\
\text { apoproteins in } \mathrm{HDL}_{2}\end{array}$} & \multirow{2}{*}{$\frac{\text { Molar ratio in } \mathrm{HDL}_{2}}{\text { ApoA-I/ApoA-II }}$} \\
\hline & ApoA-I & ApoA-II & \\
\hline $\begin{array}{l}\text { LPL activity } \\
\text { Alimentary }\end{array}$ & $-0.26(\mathrm{NS})$ & -0.21 (NS) & $0.36(P<0.05)$ \\
\hline lipemia & -0.20 (NS) & 0.22 (NS) & $-0.36(P<0.05)$ \\
\hline Percent TG & & & \\
\hline in $\mathrm{HDL}_{2}$ & 0.06 (NS) & $0.38(P<0.04)$ & $-0.50(P<0.002)$ \\
\hline HL activity & -0.36 (NS) & $0.41(P<0.02)$ & $-0.54(P<0.002)$ \\
\hline $\mathrm{HDL}_{2}$ levels & 0.35 (NS) & $-0.47(P<0.007)$ & $0.61(P<0.0001)$ \\
\hline
\end{tabular}

* No correlations existed between apoA-I and apoA-II associated with $\mathrm{HDL}_{3}$ and any of the parameters listed. 


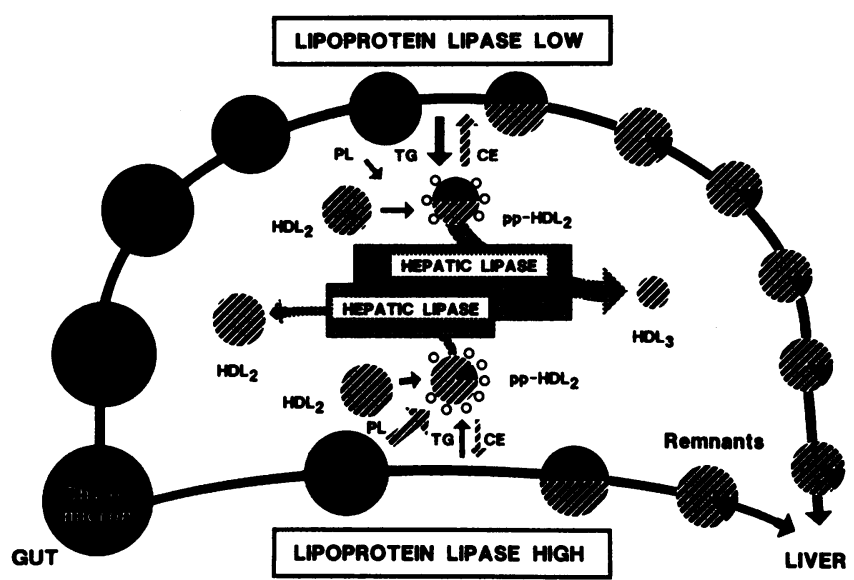

Figure 4. Model of interrelationship of LPL, postprandial lipemia, TG content of $\mathrm{HDL}_{2}$, and $\mathrm{HL}$ on $\mathrm{HDL}_{2}$ levels. In individuals with high LPL activity, there is little, if any, accumulation of chylomicrons. Chylomicron-derived phospholipids (open circles) are transferred to $\mathrm{HDL}_{2}$. HL now removes the excess phospholipid from these postprandial $\mathrm{HDL}_{2}$ particles (pp-HDL $\mathrm{HL}_{2}$ so that the phospholipid-depleted $\mathrm{HDL}_{2}$ can continue to serve as phospholipid acceptors during renewed chylomicron catabolism. Under these conditions $\mathrm{HDL}_{2}$ steady state levels are not reduced by fat intake. By contrast, when LPL activity is low, chylomicrons accumulate in the blood. Chylomicron TG (black areas), through the action of lipid transfer proteins, are transferred to $\mathrm{HDL}_{2}$ in exchange for cholesteryl esters (shaded). HL whose activity is elevated now removes not only the phospholipids from the surface, but also the TG from the core of $\mathrm{HDL}_{2}$ so that smaller $\mathrm{HDL}_{3}$ particles are formed. In this situation, HL reduces the steady state levels of $\mathrm{HDL}_{2}$ by converting some of them to $\mathrm{HDL}_{3}$.

by $\mathrm{HL}$. Indeed, the TG content of $\mathrm{HDL}_{2}$ varied inversely with $\mathrm{HDL}_{2}$ levels $(r=-0.56, P<0.0005)$. However, HL activity differed also from subject to subject and correlated inversely with $\mathrm{HDL}_{2}$ levels (Fig. $2 \mathrm{~B}$ ). At this point we have no explanation why the activity of HL is increased in individuals with low LPL activities and with low $\mathrm{HDL}_{2}$ levels.

Regarding the composition of $\mathrm{HDL}_{2}$, not only the TG content, but also the apoA-I/apoA-II molar ratio was highly variable among individuals because of differing amounts of apoA-II in $\mathrm{HDL}_{2}$ (Table IV). The higher the apoA-II content in $\mathrm{HDL}_{2}$, the higher are the proportion of $\mathrm{TG}$ in $\mathrm{HDL}_{2}$ and $\mathrm{HL}$ activity, and the lower are $\mathrm{HDL}_{2}$ levels in plasma (Table V). In a previous study, we have observed that only those $\mathrm{HDL}_{2}$ particles that contain apoA-II are converted to $\mathrm{HDL}_{3}$ by $\mathrm{HL}$ in vitro (31). Taken together, the in vitro data (31) and the data from this study suggest a possible function of apoA-II in this process: apoAII could be important for TG content of $\mathrm{HDL}_{2}$ by being involved in neutral lipid exchange, or the apoprotein could be an effector for HL. HDL containing apoA-II (in addition to apoA-I) are present both in $\mathrm{HDL}_{2}$ and $\mathrm{HDL}_{3}(38,39)$ and could represent the postulated shuttle vector in going from $\mathrm{HDL}_{2}$ to $\mathrm{HDL}_{3}(31)$ via lipid exchange and $\mathrm{HL}$ (Fig. 4) and, from $\mathrm{HDL}_{3}$ to $\mathrm{HDL}_{2}$ through assimilation by $\mathrm{HDL}_{3}$ of surface components of lipolyzed TG-rich lipoproteins (27). The study presented here, further strengthens the view that $\mathrm{HDL}_{2}$ and, thus, HDL-cholesterol should not be considered, neither biochemically nor epidemiologically, as an independent lipid transport mechanism nor as an independent risk factor for atherosclerosis, but rather as being a dependent variable to TG transport as exemplified in the postprandial phase.

\section{Acknowledgments}

The authors wish to thank Dr. G. Bengtsson-Olivecrona for providing an antiserum directed against human HL, I. Y. Chen, and I. Thandi for their expert technical assistance, and Irene Perez for typing the manuscript.

Dr. J. R. Patsch is an Established Investigator of the American Heart Association. This work was supported by grant HL-27341 from the National Institutes of Health and by a Grant-in-Aid from the American Heart Association (83-1098), with funds contributed in part by the American Heart Association, Texas Affiliate, Inc.

\section{References}

1. Miller, G. J., and N. E. Miller. 1975. Plasma high density lipoprotein concentration and development of ischemic heart disease. Lancet. i:1619.

2. Rhoads, G. G., G. L. Gulbrandsen, and A. Kagan. 1976. Serum lipoproteins and coronary heart disease in a population study of Hawaii Japanese men. N. Engl. J. Med. 294:293-298.

3. Gordon, T., W. P. Castelli, M. C. Hjortland, W. B. Kannel, and T. R. Dawber. 1977. High density lipoprotein as a protective factor against coronary heart disease. Am. J. Med. 62:707-714.

4. Berg, K., A. L. Borresen, and G. Dahlen. 1976. Serum-high-densitylipoprotein and atherosclerotic heart-disease. Lancet. i:499-501.

5. Tyroler, H. A. 1980. Epidemiology of plasma high-density lipoprotein cholesterol levels. Circulation. 62(Suppl. IV):IV-1-IV-3.

6. De Lalla, O. F., and J. W. Gofman. 1954. Ultracentrifugal analysis of serum lipoproteins. Methods Biochem. Anal. 1:459-478.

7. Patsch, J. R., S. Sailer, G. Kostner, F. Sandhofer, A. Holasek, and H. Braunsteiner. 1974. Separation of the main lipoprotein density classes from human plasma by rate-zonal ultracentrifugation. J. Lipid Res. 15: 356-366.

8. Patsch, J. R., J. B. Karlin, L. W. Scott, L. C. Smith, and A. M. Gotto, Jr. 1983. Inverse relationship between blood levels of high density lipoproteins $s_{2}$ and magnitude of postprandial lipemia. Proc. Natl. Acad. Sci. USA. 80:1449-1453.

9. Anderson, D. A., A. V. Nichols, S. S. Pan, and F. T. Lindgren. 1978. High density lipoprotein distribution. Resolution and determination of three major components in a normal population sample. Atherosclerosis. 29:161-179.

10. Rothblat, G. H., M. Bamberger, and M. C. Phillips. 1986. Reverse cholesterol transport. Methods Enzymol. 129:628-644.

11. Department of Health and Human Services. 1980. The Lipid Research Population Study Data Book: The Prevalance Study. NIH Publication No. 80-1527. National Institutes of Health, Bethesda, MD. 52-63.

12. Warnick, G. R., J. M. Benderson, and J. J. Albers. 1982. Quantitation of high density lipoprotein subclasses after separation by dextran sulfate and $\mathrm{Mg}^{2+}$ precipitation. Clin. Chem. 28:1379-1388.

13. Warnick, G. R., J. Benderson, and J. J. Albers. 1982. Quantitation of high-density-lipoprotein subclasses after separation by dextran sulfate and $\mathrm{Mg}^{2+}$ precipitation. Clin. Chem. 28:1574. (Abstr.)

14. Bartlett, G. R. 1959. Phosphorous assay in column chromatography. J. Biol. Chem. 234:466-468.

15. Patsch, W., S. Sailer, and H. Braunsteiner. 1976. An enzymatic method for the determination of the initial rate of cholesterol esterification in human plasma. J. Lipid Res. 17:182-185.

16. Lowry, O. H., N. J. Rosebrough, A. L. Farr, and R. J. Randall. 1951. Protein measurement with the Folin phenol reagent. J. Biol. Chem. 193:265-275.

17. Siedel, J., E. Hagele, J. Ziegenhorn, and A. W. Wahlefeld. 1983. Reagent for the enzymatic determination of serum total cholesterol with improved lipolytic efficiency. Clin. Chem. 29:1075-1080.

18. Nagele, U., E. O. Hagele, G. Sauer, E. Wiedemann, P. Lehmann, A. W. Wahlefeld, and W. Gruber. 1984. Reagent for the enzymatic determination of serum total triglycerides with improved lipolytic efficiency. J. Clin. Chem. Clin. Biochem. 22:165-174. 
19. Karlin, J. B., D. J. Juhn, A. M. Fless, A. M. Scanu, and A. H. Rubenstein. 1978. Measurement of human low density apolipoprotein B by radioimmunoassay. Eur. J. Clin. Invest. 8:19-26.

20. Karlin, J. B., D. J. Juhn, J. I. Starr, A. M. Scanu, C. Edelstein, and A. H. Rubenstein. 1976. Measurement of human high density lipoprotein apolipoprotein A-I in serum by radioimmunoassay. J. Lipid Res. 17:30-37.

21. Goldberg, R. B., J. B. Karlin, D. B. Juhn, A. M. Scanu, C. Edelstein, and A. H. Rubenstein. 1980. Characterization and measurement of human apolipoproteins-II by radioimmunoassay. J. Lipid Res. 21: 902-912.

22. Maciejko, J. J., and S. J. T. Mao. 1982. Radioimmunoassay of apolipoprotein A-1. Application of a non-ionic detergent (Tween-20) and solid-phase staphylococcus. Clin. Chem. 28:199-204.

23. Huttunen, J. K., C. Ehnholm, P. K. T. Kinnunen, and E. A. Nikkila. 1975. An immunochemical method for the selective measurement of two triglyceride lipases in human postheparin plasma. Clin. Chim. Acta. 63:335-347.

24. Jensen, G. L., B. Daggy, and A. Bensadoun. 1982. Triacylglycerol lipase, monoacylglycerol lipase and phospholipase activities of highly purified rat hepatic lipase. Biochim. Biophys. Acta. 710:464-470.

25. Jackson, R. L. 1983. Lipoprotein lipase and hepatic lipase. In The Enzymes. Lipid Enzymology. Vol. XVI. P. D. Boyer, editor. Academic Press, Inc., New York. 141-181.

26. Bengtsson, G., and T. Olivecrona. 1980. The hepatic heparinreleasable lipase binds to high density lipoproteins. FEBS (Fed. Eur. Biochem. Soc.) Lett. 119:290-292.

27. Patsch, J. R., A. M. Gotto, Jr., T. Olivecrona, and S. Eisenberg. 1978. Formation of high density lipoprotein ${ }_{2}$-like particles during lipolysis of very low density lipoproteins in vitro. Proc. Natl. Acad. Sci. USA. 75: 4519-4523.

28. Kinnunen, T., P. Vainio, and T. Thuren. 1981. Evidence against the role of hepatic endothelial lipase in the metabolism of plasma $\mathrm{HDL}_{2}$. Atherosclerosis. 40:377-379.

29. Kuusi, T., E. A. Nikkila, M.-R. Taskinen, and M. J. Tikkanen.
1982. Role of hepatic endothelial lipase in the metabolism of plasma $\mathrm{HDL}_{2}$ : a reply to the letter by Kinnunen et al. Atherosclerosis. 44:237240.

30. Demacker, P. N. M., P. M. J. Stuyt, A. G. M. Hijmans, and A. Van't Laar. 1983. Absence of inhibition of hepatic lipase by HDL. Atherosclerosis. 48:101-103.

31. Patsch, J. R., S. Prasad, A. M. Gotto, Jr., and G. BengtssonOlivecrona. 1984. Postprandial lipemia. A key for the conversion of high density lipoprotein ${ }_{2}$ into high density lipoprotein ${ }_{3}$ by hepatic lipase. $J$. Clin. Invest. 74:2017-2023.

32. Tall, A. R. 1986. Plasma Lipid Transfer Proteins. J. Lipid Res. 27:361-367.

33. Behr, S. R., J. R. Patsch, T. Forte, and A. Bensadoun. 1981. Plasma lipoprotein changes resulting from immunologically blocked lipolysis. J. Lipid Res. 22:443-451.

34. Deckelbaum, R. J., E. Granot, Y. Oschry, L. Rose, and S. Eisenberg. 1984. Plasma triglyceride determines structure-composition in low and high density lipoproteins. Arteriosclerosis. 4:225-231.

35. Morton, R. E., and D. B. Zilversmit. 1983. Interrelationship of lipids transferred by the lipid-transfer protein isolated from human lipoprotein-deficient plasma. J. Biol. Chem. 258:11751-11757.

36. Patsch, W., G. Schonfeld, A. M. Gotto, Jr., and J. R. Patsch. 1980. Characterization of human high density lipoproteins by zonal ultracentrifugation. J. Biol. Chem. 255:3178-3185.

37. Blanche, P. J., E. L. Gong, T. Forte, and A. V. Nichols. 1981. Characterization of human high density lipoproteins by gradient gel electrophoresis. Biochim. Biophys. Acta. 665:408-419.

38. Cheung, M. C., and J. J. Albers. 1982. Distribution of high density lipoprotein particles with different apoprotein composition, particles with A-I and A-II, and particles with A-I but no A-II. J. Lipid Res. 23:747753.

39. Atmeh, R. F., J. Shepherd, and C. J. Packard. 1983. Subpopulations of apolipoprotein A-I in human high density lipoproteins: their metabolic properties and response to drug therapy. Biochim. Biophys. Acta. 751:175-188. 